\title{
As resistências culturais enfrentadas pela mulher no âmbito das modalidades de lutas
}

\section{RESUMO}

$\mathrm{O}$ presente estudo qualitativo teve como objetivo compreender as barreiras sociais enfrentadas pelas mulheres praticantes de lutas (artes marciais ou esporte de combate). Este estudo traz artigos acadêmicos, exemplos e fragmentos de textos de conhecimento público que mostram parte do processo histórico que uma mulher enfrenta quando pratica luta. Foi elaborada uma revisão de literatura acerca do tema para encontrar a existência das barreiras sociais e quais são elas. Como consequência, esse artigo é capaz de transmitir as superações das mulheres tanto no âmbito das modalidades de lutas quanto no âmbito social. Como resultado, foi identificado alguns fatores e a existência de 5 barreiras sociais: a distinção de gênero, cultura da feminilidade, as mídias, exploração da erotização da mulher e a exclusão social da mesma. Tais barreiras são encontradas estruturadas na sociedade. E, mesmo diante disso, a mulher vem conquistando espaço na sociedade em geral e na área das lutas em particular.

PALAVRAS-CHAVE: Mulheres; Lutas; Barreiras sociais; Artes marciais; Preconceitos
Juliana de Souza

Graduada

Unimetrocamp, Faculdade de Educação

Física, Campinas,

São Paulo, Brasil

Julianasouza36@yahoo.com

D https://orcid.org/0000-0003-4401-647X

\section{Laercio Claro Pereira Franco}

Doutor

Unimetrocamp, Faculdade de Educação

Física, Campinas,

São Paulo, Brasil

laerciofranco16@gmail.com

- 1 https://orcid.org/0000-0003-1921-1652 


\title{
Cultural resistances faced by women in the context of the modalities of struggles
}

\begin{abstract}
This qualitative study aimed to understand social barriers faced by women who practice fighting (martial arts or combat sports). It brings some academic articles, examples and public known texts which shows parts of a historical process woman goes through when fight practicing. A literature review was elaborated upon the theme to find possible social barriers and what would they be. As consequence, this article was able to transmit overcoming examples of women in both contexts: of fighting modalities and within public spaces. As an outcome, this study found five mainly social barriers, which are: the distinction of gender, culture of femininity, the media, the erotization of women's bodies and behaviors and their social exclusion. Such barriers were found pervaded throughout our society culture. And, even before that, women have been conquering and exhibiting female empowerment within our society and in the context of fights (martial arts and combat sports).
\end{abstract}

KEYWORDS: Women; Fights; Social barriers; Martial arts; Prejudices

\section{Resistencias culturales que enfrentan las mujeres en el ámbito de las modalidades de lucha}

\section{RESUMEN}

El presente estudio cualitativo tuvo como objetivo comprender las barreras sociales que enfrentan las mujeres que luchan (artes marciales o deportes de combate). Este estudio trae artículos académicos, ejemplos y fragmentos de textos de conocimiento público que muestran parte del proceso histórico que enfrenta una mujer cuando practica pelear. Se preparó una revisión de la literatura sobre el tema para descubrir la existencia de barreras sociales y cuáles son. Como consecuencia, este artículo es capaz de transmitir la superación de las mujeres tanto en el ámbito de las modalidades de lucha como en el ámbito social. Como resultado, se identificaron algunos factores y la existencia de 5 barreras sociales: la distinción de género, la cultura de la feminidad, los medios de comunicación, la explotación de la erotización de las mujeres y la exclusión social. Dichas barreras se encuentran estructuradas en la sociedad. E incluso con eso en mente, las mujeres han ido ganando espacio en la sociedad en general y en el área de las luchas en particular.

PALABRAS-CLAVE: Mujeres; Luchas; Barreras sociales; Artes marciales; Prejuicios 


\section{INTRODUÇÃO}

A história das mulheres é marcada por rupturas, barreiras, persistências, transgressões, avanços e preconceitos. Elas são lutadoras da vida real e vêm conquistando seus lugares na sociedade, juntamente na área da Educação Física e expressamente nos esportes.

Historicamente na antiguidade, a mulher quase sempre teve um papel secundário. Por exemplo, na sociedade grega, um dos berços da civilização ocidental, havia uma distinção evidente de gênero, marcada por definições de cargos sociais e políticos. Enquanto os homens possuíam poder e prestígio, sendo políticos, comerciantes e guerreiros, as mulheres não eram consideradas cidadãs e deveriam ser submissas a eles. Desde criança a mulher deveria ser separada dos seus irmãos e ficar em uma parte isolada da casa o "gynaikeion". Mal podia sair na rua, e caso isso acontecesse era necessário o uso de roupas que cobrissem da cabeça aos pés, sendo acompanhadas por um homem sendo o pai ou o marido. A mulher tinha como finalidade o casamento, formar uma família para gerar novos soldados ao país (BRITO, 2018).

Com esse contexto social a mulher começa a lutar por sua autonomia e cabe aqui citar alguns exemplos apenas para encaminhar ao leitor algumas personalidades femininas que enfrentaram os preconceitos estruturais na sociedade no decorrer da história.

Um exemplo clássico é visívelna era medieval, durante a Guerra dos Cem anos (1331-1453) na França, quando uma jovem heroína francesa Joana d'Arc, nasceu em 1412, a qual presenciou quando criança o assassinato de membros de sua família por soldados ingleses. Após seus 13 anos decidida a entrar no exército, se vestiu de homem e começou a fazer os treinamentos militares, foi aceita no exército francês e chegou a comandar as tropas. Devido a importantes vitórias, causou inveja em outros líderes, foi capturada e vendida aos ingleses os quais acusaram-na de feiticeira e foi condenada a fogueira, queimada viva em 1431 (SÓ HISTÓRIA, 2009).

Outro grande nome é Agustina Domenéch (1786-1857), Espanha, em 1808, ela levou uma cesta com maçãs aos soldados artilheiros que enfrentavam as tropas de Napoleão, em Zaragoza, se deparou com os canhões desprotegidos, então, ela mesma disparou um perto do exército francês, após esse ato os soldados espanhóis voltaram as suas armas e a batalha. Ela, assim, vira capitã da artilharia (AVENTURAS NA HISTÓRIA, 2019).

Entre outros momentos, um bastante marcante para as mulheres ao redor do mundo foi com a grande mudança de vários aspectos da Revolução Industrial, a qual a mulher passou a trabalhar fora de casa e assim iniciou seu processo de ascensão e tentativa de igualdade social. 
Como citado em Goellner (2016), no Brasil com os imigrantes europeus e as ideias higienistas, as mulheres da elite começam a entrar no universo cultural do esporte, elas detinham maior circulação aos bens culturais, tendo acesso as práticas de ginástica como turfe, remo, natação, esgrima, tênis, arco e flecha e o ciclismo.

A mulher, exercitando-se fisicamente, era vista como novidade na época, pois com o romantismo na literatura, as imagens associadas a elas eram imagens delicadas, gráceis, frágeis, voltada ao casamento e a maternidade, portanto,românticas. Porém com os médicos higienistas essas ideias começam a ser alteradas com o discurso sobre os benefícios que os exercícios físicos traziam para elas, como melhoras nas condições orgânicas para enfrentarem a maternidade e embelezá-las (GOELLNER, 2016).

O pensamento higienista começou entre o final do século XIX e início do século XX, padronizando e estabelecendo funções à família brasileira, segregando as tarefas em relação aos gêneros, mulheres deveriam cuidar do lar e gerar descendentes saudáveis (MOURÃO, 2000).

A ideologia higienista contribuiu fundamentalmente para tirar a mulher do estado de segregação em relação à atividade físico-desportiva, na medida em que as representações deste ideário influenciaram a sociedade brasileira e um de seus pressupostos de saúde se identifica com a prática do movimento corporal pela mulher, de forma a incidir em uma função reprodutora mais saudável, garantindo a gestação de filhos mais fortes. (MOURÃO, 2000, p. 15).

Professores e instrutores de atividades físicas em prol desse discurso integram várias ações no plano social e educacional, pois acreditava-se no fortalecimento do corpo feminino, da sua regeneração físico-moral de que uma população só se completaria com o aprimoramento físico da mulher identificado como a célula mater da nação (GOELLNER, 2016).

Sobre o discurso acima, Sobrinho (1930) afirma que quanto mais se aprofunda nas pesquisas para solucionar os problemas da saúde humana, observa-se a importância dos exercícios físicos para a mulher, contribuindo para a conservação da saúde e da beleza, por isso, é tão importante a Educação Física às mulheres.

Contudo não iria ser fácil assim. Um renomado Fisiologista da época, Mário Carvalho Pini (1978) argumenta que a mulher até poderia participar dos esportes, porém não deveria praticar algumas modalidades (como rúgbi, futebol, lutas, entre outras), porque os treinamentos acarretariam um grande desgaste físico, além dos traumas físicos e estéticos dos contatos violentos dessa modalidade. Essas ideologias se transformaram em leis, como a promulgada no período do Estado 
Novo (1937 a 1945) e que vigorou no Brasil entre 1941 e 1975: o Decreto-lei $n^{\circ} 3.199$, cujo artigo 54 expressava que “(...) às mulheres não se permitirá a prática de desportos incompatíveis com as condições de sua natureza”.

\section{ESPORTE, LUTAS E MULHERES}

E por que esportes como a luta são martirizados quando se trata de mulheres praticantes? Explicam Souza e Altmann (1999), os esportes competitivos, violentos, com contato físico, são formas de tornar um menino em homem, aumentando a sua virilidade, masculinidade, capacidade de desprezar a dor, controle do corpo e vontade de ganhar, ou seja, são esportes cujos rituais balizam questões próprias de uma masculinidade ideal a ser atingida e conquistada.

O suor excessivo, o esforço físico, as emoções fortes, as competições, a rivalidade consentida, os músculos delineados, os gestos espetacularizados do corpo, a liberdade de movimentos, a leveza das roupas e a seminudez, práticas comuns no universo da cultura física, quando relacionadas à mulher, despertavam suspeitas porque pareciam abrandar certos limites que contornavam uma imagem ideal de ser feminina. Pareciam, ainda, desestabilizar o terreno criado e mantido sob domínio masculino cuja justificativa, assentada na biologia do corpo e do sexo, deveria atestar a superioridade deles em relação a elas (GOELLNER, 2005, p. 92).

A imagem da mulher mostrando que não é frágil, assustava. Sobre isso Mourão (2002) diz que as mulheres que praticam os esportes classificados para os homens são rotuladas de masculinas, e, quandoo fazem, sofrem com o preconceito tanto de homens quanto de mulheres.

Aos poucos a mulher desmistifica a ideia de um corpo frágil e submisso e começa a ocupar seu espaço no mundo das lutas. Daniel S. Silva. et al, (2019), descreveu a mulher atleta com uma nova rotina, corrida com treinos intensos, hábitos alimentares mais saudáveis acarretando em mudanças comportamentais. Para algumas pessoas tais hábitos são negativos devido a mudança brusca do estilo de vida da mulher, principalmente pela masculinização, desde que ela não deixe de lado os aspectos associados a feminilidade.

Devido a esses estereótipos das lutas serem violentas e de domínio dos homens impostos pela sociedade, a entrada da mulher na modalidade das lutas foi tardia. Aqui no Brasil a primeira luta oficial do Jiu-jitsu Feminino, por exemplo, foi em 1985 (SILVA. et al, 2019), o Judô em 1980 
oficializado para competição (SILVA, 1994) e o MMA (Mixed Martial Arts, ou Artes Marciais Mistas) só em 2003 registrou a primeira luta oficial (FERNANDES et al, 2015).

Mesmo com tanto preconceito, a mulher tem seu cenário atual nos tatames. No Jiu-jitsu Feminino Kyra Gracie é um dos grandes fenômenos do passado, algumas gerações de lutadoras estão listadas na revista Ciência Atual (2019) como Mackenzie Dern, Gezary Matuda, Ana Carolina Vidal e Andresa destaque faixas preta do ano de 2013. Em 2014, Janni Larson e Tammi Musumeci. 2015, Monique Elias, Dominyka Obelenyte e Angélica Galvão. Em 2016/17, Tayane Porfírio, Nathiely Caroline, Ana Carolina Vieira, a "Baby", Talita Alencar, Thamires Aquino, Bianca Basílio e a canadense Yacinta Nguyen. No Brasil o Ranking atual em 2019, tem os nomes Bianca Barbosa Basilio, Carina Curvelo e Claudia Fernanda Onofre Valim Doval.

No UFC um dos grandes nomes foi Ronda Rosey ex-campeão na categoria peso-galo em 2016 e que abriu caminho para a popularização da mulher no MMA. Outro nome é a Cris Cyborg (Cristiane Justino), lutadora brasileira campeã do UFC na categoria dos penas. Atualmente a mulher aparece em várias categorias nesse evento: Peso-Palha, Peso-Mosca, Peso-Galo e Peso Pena, com destaque para a brasileira Amanda Nunes, campeã nas duas últimas. O ranking nesse grande evento é composto no total por 60 mulheres participantes.

No Judô não podemos deixar de citar a brasileira Edinanci Silva, pioneira a alcançar duas medalhas em mundiais (bronze em 1997, 2003) e ouro nos Jogos Pan-Americanos de 2003 e 2007. Edinanci participou de quatro edições dos Jogos Olímpicos (1996, 2000, 2004, 2008) (SOUZA, 2016). Outros nomes que não podem faltar são a Sarah Menezes medalhista de ouro nos Jogos de Londres em 2012, primeiro êxito do judô feminino brasileiro em uma Olímpiada. Rafaela Silva, campeã olímpica em 2016 e mundial em 2013 e a Mayara Aguiar bicampeã mundial (2014, 2017) e medalhista Olímpica (2012, 2016) (REDE DO ESPORTE, 2018).No Ranking Mundial de 2019 estão nomes, como: Gabriela Chibana, Larissa Pimenta, Tamires da Silva e Alexia Castilhos.

Já no Boxe, a pioneira é a francesa Myriam Lamare, totaliza 23 lutas profissionais, apenas com 3 derrotas. Sarah Ourahmoune participou de 260 lutas, campeã do boxe amador e tricampeã no boxe francês. No Brasil, há algumas lutadoras como Adriana Araújo, bronze nos Jogos Olímpicos de Londres (2012),Clélia Costa, bronze no Campeonato Mundial de Boxe Olímpico (1914), e Rose Volante, primeira mulher brasileira a conquistar um título da Organização Mundial do Boxe (OMB), em 2017.

Há outros grandes exemplos, como da medalhista olímpica Natália Falavigna no Tae-kwon-do; a possibilidade de medalhas no Karatê em Tóquio 2021 e de outras modalidades, como na Capoeira e os crescentes Muay Thai e o Krav-Magá. 


\section{Conceituação, definição e classificações de lutas}

Existem diversas definições e classificações para as Lutas. Nos parâmetros curriculares nacionais (PCN), por exemplo, elas são descritas da seguinte maneira:

As lutas são disputas em que o(s) oponente(s) deve(m) ser subjugado(s), mediante técnicas e estratégias de desequilíbrio, contusão, imobilização ou exclusão de um determinado espaço na combinação de ações de ataque e defesa. Caracterizam-se por uma regulamentação específica, afim de punir atitudes de violência e de deslealdade. Podem ser citados como exemplo de lutas desde as brincadeiras de cabo de guerra e de braço de ferro até as práticas mais complexas da Capoeira, do Judô e do Karatê (BRASIL, 1997, p. 37).

Sobre outra definição de lutas Mocarzel (2011) relata:

Uma proposta para conceituação de "lutas" seria: conjunto de técnicas estruturadas para combates físicos com praticantes desarmados ou armados, que buscam primordialmente a autodefesa e o desempenho físico, sem considerar questões filosófico-culturais no momento de criação ou utilização de suas técnicas (MOCARZEL, 2011, p. 13).

Nesse âmbito das lutas há publicações de subconjuntos, tais como esportes de combate e as artes marciais.As artes marciais se referem a lutas guiadas por princípios socioculturais, as vezes religiosose filosóficos, essas práticas derivam de técnicas de guerra, ataque e defesa. Desta forma:

A arte marcial faz referência a um conjunto de práticas corporais que são configuradas a partir de uma noção aqui denominada de "metáfora da guerra", uma vez que essas práticas derivam de técnicas de guerra como denota o nome, isto é, marcial (de Marte, deus romano da guerra: Ares para os gregos) (CORREIA; FRANCHINI, 2010, p. 01).

Ainda sobre as artes marciais, Mocarzel (2011) também as define: 
Artes Marciais" seriam: todas as técnicas marciais de caráter sócio-educativas, estruturadas em métodos didático-pedagógicos, que por sua vez são embasados por uma ou múltiplas filosofias que pregam harmonia, saúde, qualidade de vida e acima de tudo a paz por seus praticantes (MOCARZEL, 2011, p. 15).

Exemplos de tais lutas são: Sumô, Kung Fu, Capoeira, Judô, Ju-jítsu, Aiki dô, Kenjutsu, Kendô, Tai Chi Chuan, Krav-Magá, entre outras.

Para Martins e Kanashiro (2010), o objetivo das artes marciais era a sobrevivência, porém com o tempo surgiu outros significados como a espiritualidade e disputa. Na atualidade algumas ainda possuem o objetivo de sobrevivência, já outras é o alto rendimento. Com esse novo objetivo é possível verificar a modificação de algumas modalidades de lutas de combate que passaram de arte marcial para uma luta esportivizada.

A esportivização das modalidades de artes marciais, acarretam uma mudança relacionada aos princípios filosóficos os quais abordam o respeito, como se portar e ser um bom cidadão para o esporte de alto rendimento focado em competições e vitórias (MONTEIRO, 1998).

Sobre o discurso dessa mudança Nascimento e Almeida (2007) definem os esportes de combate como modalidades que aplicam técnicas, táticas, imobilização, estratégia de oposição, a exclusão de determinado espaço e o desequilíbrio para vencer. Além da utilização de regras, integridade física e moral do oponente, diferenças de gêneros, peso e altura.

Elias e Dunning (1992), afirmam que o esporte de combate são as artes marciais transformadas em esporte espetáculo, controlado por regras e os golpes os quais são selecionados para diminuir o grau de danos no oponente.

Em relação a discussão acima Bracht, 1997, diz:

(...) as organizações esportivas que dominam o esporte espetáculo, buscam incorporar/encampar as formas alternativas de prática esportiva que surgem para não perder o poder de determinar as formas legitimas de sua prática, daí porque também, as formas alternativas de práticas corporais logo sofrem pressão no sentido da sua esportivização (...) (BRACHT, 1997, p. 14).

Alguns exemplos de esporte de combate podem ser os olímpicos:Esgrima, Judô, Boxe, Taekwondo, Karatê e Greco-romana.

Algumas mulheres procuram por essas modalidades pela identificação pessoal, qualidade de vida, bem-estar, estética e a questão da segurança devido à violência existente contra a mulher (GLOBO ESPORTE, 2014). 
Diante desse cenário e abordagem histórica, social e cultural, percebemos a necessidade de um estudo mais aprofundado em relação ao espaço da mulher em um mundo tradicionalmente masculino: a luta. Em face deste contexto, o objetivo deste estudo é compreender as barreiras sociais enfrentadas pelas mulheres praticantes de lutas.

\section{MÉTODOS}

Esta pesquisa decorre de uma abordagem metodológica qualitativa com o intuito de agrupar dados de forma narrativa, através de uma revisão de literatura. De acordo com Thomas e Nelson (2002) a pesquisa qualitativa tem como objetivo o princípio do fenômeno, desenvolvendo hipóteses a partir das observações. Entendemos como fenômeno a ser explicitado as barreiras sociais enfrentadas pelas mulheres praticantes de lutas, sendo necessário classificar e discutir os artigos, capítulos de livros, filmes e outros trabalhos publicados referentes a este tema.

O método de pesquisa utilizado é o de revisão de literatura, onde os autores Thomas e Nelson (2002, p. 33) “confirmam que a revisão é uma avaliação crítica de pesquisa recente sobre determinado tópico (...). Envolve análise, avaliação e integração da literatura pública, direcionando a conclusões sobre descobertas de pesquisas feitas até o momento". O tipo da revisão de literatura é a narrativa a qual tem como finalidade mapear o entendimento de uma questão abrangente (análise de literatura), o pesquisador estabelece os artigos e informações mais relevantes e a há interferência de ação subjetiva (CORDEIRO et al., 2007).

Através da revisão de literatura narrativa, a busca das informações indispensáveis para o artigo referentes ao tema "mulher praticante de lutas" foi realizada nas buscas de dados online Scielo e Google Acadêmico para direcionar aos periódicos, artigos e os capítulos de livros relacionados à discussão proposta nesta pesquisa e foram empregadas as seguintes palavras-chave: mulher, lutas, artes marciais, dificuldades e preconceitos. Porém foram encontradas poucas referências públicas, totalizando em um número de nove artigos específicos. Também ocorreu a mesma dificuldade para encontrar livros referentes, pois se trata de um assunto pouco comentado.

Com isso, a busca por tais informações foi no rastreio de dados online na plataforma Google para poder encontrar referências sobre mulheres guerreiras na antiguidade e filmes relacionados a imagens da mulher no âmbito das modalidades de lutas já reconhecidas mundialmente. As palavras chaves foram: Principais guerreiras da antiguidade, Joana D'arc, Agustina Domenich, Mulan, Menina de Ouro, As panteras, Mulher Gato. 
Através dessa busca foram encontrados 3 sites sobre as principais guerreiras e 4 sites referentes a críticos dos filmes. Estes foram escolhidos devido a sua popularidade.

A pesquisa tem caráter exploratório, com o intuito de agrupar informações relevantes da área afim de proporcionar mais informações sobre o assunto, possibilitando a familiarização com o tema (PRODANOV; FREITAS, 2013).

Para buscar mais informações sobre o número atual de mulheres atletas para comparar com o número de homens e também analisar se houve um aumento do número dessas mulheres, para tal referência foi utilizado dois sites oficiais da Confederação Brasileira de Jiu-jitsu brasileiro e de Boxe. Palavra-chave: Ranking.

Contudo, foram pesquisadas dezenas de outras publicações menos populares que embasaram este texto e reforçaram as referências bibliográficas na construção do mesmo.

A relevância da realização desta pesquisa bibliográfica sobre as resistências culturais enfrentadas pela mulher no âmbito das lutas deve ser atribuída a uma revisão com o intuito de apresentar as informações sobre este tema para obter a familiarização e a partir disto construir pensamentos e reflexões.

\section{RESULTADOS E DISCUSSÕES}

Após realizar a análise das informações através da revisão de literatura em artigos, sites, periódicos e filmes a respeito das resistências culturais enfrentadas pela mulher no âmbito das lutas, foi observada a existência de barreiras, sendo encontradas 5 barreiras sociais enfrentadas por elas.

No quadro 1 a seguir agrupamos quais são as barreiras e quais foram os autores que advogam o assunto.

Quadro 1 - As Barreiras Sociais enfrentadas pelas mulheres praticantes de lutas.

\begin{tabular}{|c|c|}
\hline BARREIRAS SOCIAIS & REFERÊNCIAS \\
\hline $1^{\text {a }}$ Distinção de gêneros & $\begin{array}{l}\text { Brito (2018), Mello (2002), Mourão et al., } \\
\text { (2018), Fan (2018), Lovisolo et al., (2006) }\end{array}$ \\
\hline $2^{\mathrm{a}}$ Cultura da feminilidade & $\begin{array}{l}\text { Goellner (2016), Sobrinho (1930), Pini (1978), } \\
\text { Decreto-lei n }{ }^{\circ} 3.199 \text { (1941), Souza et al.(1999), } \\
\text { Mourão (2002), Adelman (2003) }\end{array}$ \\
\hline $3^{\text {a }}$ Mídias & Buitoni (1981), McQuail (2003) \\
\hline $\begin{array}{l}4^{\mathrm{a}} \text { Exploração da erotização da } \\
\text { mulher }\end{array}$ & $\begin{array}{l}\text { Ferreti et al., (1981), Cunha (2004), Canhisares } \\
(2019)\end{array}$ \\
\hline $5^{\mathrm{a}}$ Exclusão da mulher & $\begin{array}{l}\text { Altemann (1998), Thorne (1993), } \\
\text { (1992), Thomazini et al., (2008) }\end{array}$ \\
\hline
\end{tabular}




\section{O cenário}

Essas barreiras nos trazem a indagação sobre as conjunturas e circunstâncias que levaram a esse enquadramento. O cenário das mulheres nas lutas na década de 1970 no Brasil, era constituído da primeira, segunda e quinta barreira social (distinção de gêneros, a cultura da feminilidade e a exclusão da mulher), pois havia o Decreto-lei n 3.199, o qual proibia a participação das mulheres em esportes violentos, "não aderentes a sua natureza frágil". Elas podiam lutar escondidas. Após o decreto ser abolido em 1975, começa a procura de mulheres em tais práticas.

Ao redor do mundo esse cenário começa a evoluir, em 1971, acontece a primeira Competição Internacional Feminina do secular Judô a ser reconhecida no mundo, com 110 inscrições ao todo. Em 1977, aconteceu o primeiro Campeonato Pan-Americano de Judô Feminino (SILVA, 1994).

Nos anos 1980 e 1990 há uma maior procura de mulheres em relação as práticas corporais consideradas violentas e típicas masculinas, tais como o futebol, o judô, o polo aquático e o handebol (GOELLNER, 2005).

\section{A rotulação de gêneros presente na sociedade e nas lutas}

Afirmam Lovisolo, Soares e Bartholo (2006) que a mulher veio para ficar no esporte, encaixar sua rotina com os treinos e mostrar seus valores e princípios, exibindo assim sua representação nesse meio, sem necessidade de se comparar aos homens.Os termos sexo e gênero não se confundem, já que o primeiro é questão biológica, enquanto o segundo é classificação gramatical e não cabe, neste estudo, polemizar a utilização muitas vezes equivocada do termo gênero. Utilizaremos este termo em sua forma simples e genérica.

Hoje em dia as mulheres modernas criam e organizam suas rotinas de acordo com as suas diversas atividades diárias com treinos, trabalho e família. Adelman (2003), referenciou, que em alguns casos, os maridos vão às competições ou ficam em casa cuidando dos filhos enquanto as esposas treinam.

Infelizmente ainda em 2020 existem preconceitos enfrentados pelas mulheres, não só no mundo das lutas, especificamente o principal foco dessa pesquisa, o qual ainda sofre com a masculinização, a rotulação dos gêneros presentes no tatame e a falta de divulgação das mídias. Notadamente, a mulher não quer ser homem, e sim uma mulher lutando, sem perder a sua vaidade, 
o seu jeito de ser. A mulher não deixa de ser mulher só porque luta. Esses argumentos tentam derrubar o estereótipo de que a luta pode influenciar na gestualidade da mulher. Com essa imagem da qual a luta interfere na feminilidade da mulher, surge o preconceito em relação a sexualidade da mulher, rotulando-a de homossexual, inclusive como se isso fosse um defeito.

Sobre a rotulação dos gêneros, é bem evidenciado, durante todo o processo da criança, a qual recebe informações que existem coisas de meninos e de meninas. Quando a mulher fica grávida a sociedade já impõe que filho se situará no "mundo azul" e filha no "mundo rosa". Com a criança maior o direcionamento começa pelas brincadeiras: meninos com carrinho, armas, bola, super-heróis e às meninas, panelas, bonecas, casinha e princesas. Nas modalidades esportivas meninos devem jogar futebol ou lutas e meninas jogar voleibol ou danças. Sobre esse discurso Mello (2002) afirma que através de uma sociedade sexista é transmitido às crianças que meninos e meninas são opostos. Esse comportamento é percebido pelas brincadeiras, brinquedos e nos esportes. Em seguida vem as instituições familiares e educacionais dificultam o desenvolvimento corporal amplo: meninos precisam ter características masculinas e meninas características femininas.

Mello (2002) ainda diz que as meninas são poupadas de algumas atividades físicas, obtendo uma capacidade de movimento menor nos esportes devido o discurso sexista do corpo da mulher ser frágil. Nessas condições a criança é influenciada a desejar uma brincadeira ou um esporte, não sendo o que ela realmente deseja. Um exemplo da influência dos pais é exemplificado por Mourão e Souza (2007) que entrevistaram a judoca Kasue Ueda. Ela relatou que seu pai ensinava todas as técnicas de judô apenas para seu irmão e para ela somente algumas, valorizando mais o filho devido o conceito de que o menino deve ser mais habilidoso.

\section{Educação Física escolar, lutas e suas relações de gêneros}

Ainda sobre essa cultura sexista existe o preconceito na Educação Física, acontecendo em vários âmbitos, sendo muito comum a exclusão da mulher, tanto por uma simples demonstração feita por um homem a pedido do professor, quanto entre os próprios alunos homens os quais preferem treinar (jogar) com outro homem.

Um estudo etnográfico realizado por Samuel Thomazini, Cláudia Emília Moraes e Felipe Almeida (2008) com lutadores e uma lutadora de MMA, analisaram as representações relacionadas a figura feminina naquele local, observou que as mulheres eram consideradas estranhas ali ou 
presenças submissas aos homens, porém alguns lutadores respeitavam, valorizando a presença da lutadora.

Em Belo Horizonte, Altemann (1998), relata que nas escolas, os meninos ocupam espaços mais amplos que as meninas nos esportes, por estar vinculado a figura de uma masculinidade forte, violenta e vitoriosa. Isso também ocorre em outras escolas pelo mundo. Nas escolas norte-americanas, Thorne (1993) discursa que os meninos ocupam dez vezes mais espaço do que meninas durante o recreio, praticando esportes coletivos, já as meninas ficavam em espaços menores e próximos ao prédio, com a proteção dos adultos, e quando meninas jogavam os meninos invadiam e interrompiam os jogos femininos.

Para sanar o problema da exclusão da mulher nos esportes os professores adaptam regras de jogos em qualquer modalidade inclusive nas lutas para todos participarem. Como afirma Louro (1992), adaptar as regras representa uma forma de ajustar o jogo, consagrando-se a ideia de que o feminino é um desvio construído do masculino.

\section{Mídias e suas influências}

Mais um preconceito é se referindo as mídias, as quais não transmitem e nem divulgam as lutas femininas com a mesma frequência das lutas masculinas. Os programas femininos são voltados para assuntos referentes a beleza, moda, culinária, decoração e maternidade (BUITONI, 1981). Em razão do que a mídia impõe e, ao mesmo tempo, reflete na sociedade, incluímos neste estudo alguns exemplos midiáticos de exposição da mulher em temas tradicionalmente masculinos.

McQuail (2003) aborda sobre a baixa representação das mulheres nas mídias em relação aos homens comparando estudos feitos em diversos países, na França apenas 17\% do público entrevistado ou mencionado eram mulheres, na Finlândia 22\% e no Reino Unido menor ainda com $13 \%$. Ele também relata que a mulher tem a sua apresentação erotizada, influenciando a visão do papel social da mulher. Existem diversos exemplos midiáticos dessa visão.

Sobre a representação da erotização da mulher, "cultura feminina", transmitida pela mídia nos filmes de mulheres lutadoras, como por exemplo "Mulher Gato" (Cat- Woman), é visível a sensualidade da protagonista, aliada à sua super força. (FERRETTI; KNIJNIK, 2007). Sobre esse assunto o crítico Cunha (2004) declara que a atriz Halle Berry, é uma mulher bonita e foi usada como garota propaganda com roupa de couro, chicote e um rebolado exagerado, tudo isso para dar um tom sexy e fetichista a personagem. 
Outro filme que aborda o assunto sobre a hiper sexualização da mulher é "As Panteras". Segundo a crítica Canhisares (2019) a direção do filme obtém um olhar totalmente masculino, dando a entender que a hiper sexualização era comum, focando as câmeras, na adaptação do filme em 2000, mais no decote e na cintura das atrizes do que na altura dos olhos.

Já no filme "Menina de Ouro", a visão sobre a mulher dentro das lutas como o boxe, ganha uma visualização maior. Krivochein (2005) comenta que a atriz do filme não é mostrada como sexy, fetichista ou cômica, porém alguém determinada, apaixonada e focada em seu trabalho. A personagem durante o filme se desenvolve fisicamente e emocionalmente.

Mais um filme que valoriza a mulher dentro do âmbito das lutas é o filme chamado "Mulan" (1998), o qual representa uma menina que deveria obedecer a tradição de sua família em casar e ser dona de casa, porém ela decide tomar outro rumo, corta seu cabelo e se alista no exército para tornar-se soldado. Ressalta Fan (2018), o filme traz várias situações as quais incomodam os homens, situações estas que podem ser rotuladas como masculinas. O filme engloba ensinamentos com base do porquê o machismo é desagradável e a importância dos gêneros.

Um marco de enfrentamento das barreiras sociais na vida real, aconteceu em Nova York quando a judoca Rusty Kanokogi, cortou seus cabelos, enfaixou os seios para esconde-los e entrou no campeonato da YMCA, passando-se por homem, lutou e ganhou o título de sua categoria. Quando o fato foi descoberto houve o cancelamento das suas vitórias (GOELLNER, 2005).

Nesse período ocorreu o tão esperado Campeonato Mundial de judô Feminino, que contou com a presença de 149 atletas de 27 países e 1.000 espectadores durante os dias da competição. Pois veio acontecer após 24 anos após o primeiro Campeonato Mundial Masculino ocorrido em 1956 (SILVA, 1994).

Aos poucos esse cenário se amplia e a mulher conquista novos espaços em outras modalidades de lutas. No Brasil o Jiu-jitsu tornou-se legal em 1970, as mulheres engajam em 1985 (SILVA. et al, 2019). Introduzido no Mundial da IBJJF em 1998, a categoria feminina, passou por mudanças desde a primeira edição em um mundial. Uma dessas mudanças foi a divisão de peso que era apenas entre leve e pesado, e englobava as faixas roxa, marrom e preta. O primeiro destaque foi para Rosângela "Zanza” Conceição, atleta da histórica Universidade Gama Filho, a qual representou o Brasil no Wrestling nos Jogos Olímpicos de Atenas, em 2004 (SOUZA, 2017).

Outra modalidade é a milenar Luta Olímpica, presente no programa olímpico desde 1896, mas que só foi permitida a entrada feminina na edição de 2004, em Atenas. Outro esporte da antiguidade conhecido como pugilismo, o boxe feminino foi reconhecido pela AIBA (International Boxing Association Amateur) somente em 1994. A Federação Internacional de Boxe (FIB) em 
novembro de 2010, coroou sua primeira campeã, Daniella Smith (IBF, 2020), mas só entrou para o programa olímpico em 2012, em Londres.

Não menos importante que as outras modalidades e a mais complexa para a aceitação da mulher foi o MMA, identificada pelo agrupamento de várias artes marciais. O UFC (Ultimate Fighting Championship) teve sua primeira edição em 1993, nos Estados Unidos e, só após 20 anos, passou a ter sua primeira categoria feminina. Anteriormente, o próprio presidente contrariava veementemente a participação de mulheres na competição (JARDIM, 2018).

Nesse mesmo ano em 2013, a atleta Ronda Rousey adentrava a arena para a primeira luta feminina de MMA, marcando a história do UFC. Sobre tal efeito da ruptura de paradigmas vencido pelas mulheres e o sucesso alcançado, o presidente da organização Dana White afirmou que Ronda é uma verdadeira pioneira que ajudou a ele, pessoalmente, e a muitas outras pessoas, a olhar diferente para as mulheres em esportes de combates. White disse ainda que Ronda se tornou um ícone global e se tornou um modelo no processo que hoje contempla lutadoras incrivelmente talentosas, produzindo algumas das melhores lutas do UFC (WHITE, 2018). Hoje em dia, em vários eventos do UFC, o confronto das mulheres é a principal luta da noite.

O reconhecimento da mulher através das vitórias não só das lutas, mas também das barreiras sociais aumentam e as lutadoras ganham espaço nos Jogos Olímpicos.

O quadro a seguir exibe a relação da entrada das modalidades de lutas masculinas e femininas nas Olímpiadas.

Quadro 2 - Início das modalidades de lutas masculinas e femininas nos Jogos Olímpicos.

\begin{tabular}{|l|c|c|}
\hline MODALIDADE & $\begin{array}{c}\text { DATA DO } \\
\text { MASCULINO }\end{array}$ & $\begin{array}{c}\text { DATA DO } \\
\text { FEMININO }\end{array}$ \\
\hline Judô & 1964 & 1992 \\
\hline Taekwondo & 2000 & 2000 \\
\hline Wrestling & 1896 & 2004 \\
\hline Boxe & 1904 & 2012 \\
\hline
\end{tabular}

É possível observar grandes hiatos da entrada da mulher em relação ao homem, contudo, ela vem conseguindo vencer as barreiras sociais, sendo reconhecida e conquistando seu espaço nos Jogos Olímpicos.

$\mathrm{O}$ ano de inclusão do boxe feminino, também foi marcante pelo fato de ter sido a primeira vez que as mulheres competiram em todos os esportes dos Jogos Olímpicos. Nos Jogos do Rio de Janeiro, Rio 2016, a participação feminina bateu recorde com 45,2\% (de 11.444 atletas, 5.176 eram mulheres). Nos próximos Jogos Olímpicos, em Tóquio, espera-se que esse número chegue à 48\% (REDE DO ESPORTE, 2018). 
Para sanar as barreiras de distinção de gêneros e a exclusão das mulheres, ocorrerão algumas pequenas mudanças, porém significantes no mundo das mulheres, para as próximas disputas olímpicas, realizada pelo COI (Comitê Olímpico Internacional), tais mudanças referem-se ao boxe substituindo dois eventos masculinos por dois femininos e no judô a inclusão da disputa por equipe mista (REDE DO ESPORTE, 2018).

Também é importante considerar o aumento do número de mulheres praticantes e atletas de lutas, mesmo que ainda seja menor que o dos homens, esse aumento foi significativo devido ao longo trajeto cheio de obstáculos enfrentados por elas. Os rankings de algumas modalidades mostram esses dados. Vamos citar os exemplos da Confederação Brasileira de Jiu-Jitsu (CBJJ) e da Confederação Brasileira de Boxe (CBBoxe)

No ranking da CBJJ coletou-se as seguintes informações: Na competição kimono (Gi), adulto, faixa preta: 268 mulheres e 1645 homens. E na competição sem kimono (No Gi), feminino, adulto, faixa preta: 129 mulheres e 843 homens.

No Ranking da CBBoxe: Feminino Elite: 57 atletas: categoria mosca (51kg) 16 atletas, categoria pena $(57 \mathrm{~kg}) 15$ atletas, categoria leve $(60 \mathrm{~kg}) 13$ atletas, meio médio ligeiro $(69 \mathrm{~kg}) 6$ atletas, categoria médio (75kg) 7 atletas. No Masculino Elite: 93 atletas: categoria mosca (52kg) 10 atletas, categoria galo (57kg) 10 atletas, categoria meio médio ligeiro (63kg) 10 atletas, categoria meio médio $(69 \mathrm{~kg}) 10$ atletas, categoria médio $(75 \mathrm{~kg}) 15$ atletas, categoria médio pesado $(81 \mathrm{~kg}) 11$ atletas, categoria pesado $(91 \mathrm{~kg}) 14$ atletas, categoria super pesado (+91) 13 atletas. No Feminino Juvenil: 10 atletas e Masculino Juvenil: 55 atletas.

Esses exemplos demonstram o crescimento da participação da mulher em ambientes antes exclusivamente masculinos.

\section{CONSIDERAÇÕES FINAIS}

É importante salientar que o percurso histórico e social da mulher, buscando pelo seu reconhecimento, foi árduo. Tal exemplo foi observado no âmbito das lutas, onde foram encontrados 5 preconceitos (barreiras) referentes a prática da mulher, tais preconceitos são a distinção de gêneros, cultura da feminilidade, as mídias, exploração da erotização da mulher e a exclusão da mesma, conforme quadro apresentado anteriormente.

Isso acarretou um início com poucas praticantes, sendo que essa minoria, muitas vezes, praticava escondida ou se passando por homem. Isso foi observado nas academias de lutas as quais possuem a maioria de praticantes e instrutores homens, esse assunto também foi evidenciado no 
estudo de Samuel Thomazini, Cláudia Emília Moraes e Felipe Almeida (2008) com lutadores e uma lutadora de MMA.

Mesmo diante dessas situações as mulheres não se calam e continuam lutando e mostrando seu mérito dentro desse campo. Através disso conquistaram lugares em várias modalidades de lutas e nos Jogos Olímpicos. Também foi possível identificar nos rankings atuais que o número de atletas aumentou significativamente ao longo de toda história.

O grande público de atletas ainda são homens, e possuem uma disparidade no número em relação a mulher, entretanto vale destacar toda a trajetória da mulher para conseguir chegar nesses números de mulheres atletas das modalidades de lutas. Nota-se que é um processo longo, porém houve um imenso progresso. A participação masculina nas lutas é milenar e a da mulher conta com poucas décadas.

Diante das reflexões pospostas, pode se observar que tais preconceitos surgem de uma herança cultural a qual é estrutural e está impregnada na sociedade desde questões de cargos em empresas, política, autonomia e esportes, entre outros.

Porém mesmo com tanta dificuldade a mulher vem mostrando seu espaço na sociedade, desde a antiguidade com mulheres lutando em guerras, quebrando o paradigma de um corpo frágil e invadindo o ambiente das lutas com grandes nomes de guerreiras, vencendo sua exclusão em práticas esportivas e minimizando sua imagem voltada para a erotização.

A mulher se apresenta historicamente rompendo as barreias sociais de suas épocas evidenciando sua capacidade física, destreza, coragem e emancipação. Dessa maneira, conquista seu espaço no âmbito das lutas acarretando em mudanças na sociedade, adquirindo lugar e respeito na esfera social. Podemos ver, então o início do empoderamento feminino, não para ser mais que o homem. Apenas ter direitos e prerrogativas iguais.

\section{REFERÊNCIAS}

ABRANTES, Beatriz. Mulheres de Atenas: entenda a crítica de Chico Buarque. 2018. Disponível em: https://www.stoodi.com.br/blog/2018/06/25/mulheres-de-atenas/. Acesso em: 02 dez. 2019.

ALDEMAN, Miriam. Mulheres atletas: re- significações da corporalidade feminina. Revista estudos feministas. Florianópolis, v. 11, n. 02, p, 445-465.

ALTMANN, Helena. "Rompendo fronteiras de gênero: Marias (e) homens na educação física". Dissertação de mestrado em educação. Belo Horizonte: UFMG, 1998, 111p.

AVENTURAS NA HISTÓRIA. De boadicea a Joana D'arc: 10 guerreiras que superaram os homens nos campos de batalha. São Paulo, 2019. Disponível em: 
https://aventurasnahistoria.uol.com.br/noticias/almanaque/historia-mulheres-em-campo-de-batalha.phtml . Acesso em: 05 dez. 2019.

BRACHT, Valter. Sociologia Crítica do Esporte: uma introdução. Vitória: UFPR, 1997.

BRASIL. Decreto-Lei n³.199, de 14 de abril de 1941. Estabelece as bases de organização dos esportes em todo o país. Disponível em: http://www.planalto.gov.br/ccivil_03/Decreto-Lei/1937-1946/Del3199.htm . Acesso em: 19 out. 2019.

BRASIL. Secretaria de Educação Fundamental. Parâmetros curriculares nacionais: Educação Física / Secretaria de Educação Fundamental. Brasília: MEC/SEF, 1997. 96p.

BRITO. R. Mulheres de Atenas: entenda a crítica de Chico Buarque. 2018. Disponível em: https://www.stoodi.com.br/blog/2018/06/25/mulheres-de-atenas/. Acesso em: 02 dez. 2019.

BUITONI, Dulcília Helena Schroeder. Mulher de papel: a representação da mulher na imprensa feminina brasileira. São Paulo: Edições Loyola, 1981.

CANHISARES. Mariana. As Panteras. 2019. Disponível em: https://www.omelete.com.br/filmes/criticas/as-panteras . Acesso em: 22 nov. 2019.

CONFEDERAÇÃO BRASILEIRA DE BOXE. Ranking. 2020. Disponível em: https://www.ibf-usba-boxing.com/index.php/about/history-of-ibf. Acesso em: 03 abr. 2020.

CONFEDERAÇÃO BRASILEIRA DE JIU-JITSU. Ranking. 2019. Disponível em: https://cbjj.com.br/ranking/. Acesso em: 19 out. 2019.

CORDEIRO, Alexander Magno. et al. Revisão sistemática: uma revisão narrativa. Revista do Colégio Brasileiro de Cirurgiões. Rio de Janeiro, v.34, n. 06, nov, 2007.

CORREIA, Walter Roberto; FRANCHINI, Emerson. Produção acadêmica em lutas, artes marciais e esportes de combate. Motriz. Rio Claro, v.16 n.1 p.01-09, 2010.

CUNHA, Rodrigo. Mulher-Gato. Cine-players, 2004. Disponível em:

http://www.cineplayers.com/critica.php?id=282. Acesso em: 25 out. 2019.

ELIAS, Norbert. \& DUNNING, E. A Busca da Excitação. Lisboa: Diefel, 1992.

FAN. Ritter. Crítica Mulan (1998). 2018. Disponível em:

https://www.planocritico.com/critica-mulan-1998/. Acesso em: 22 nov. 2019.

FERNANDES. Et al. Mulheres em combate: representações de feminilidades em lutadoras de boxe e MMA. Revista da educação física. Maringá, v.26, n. 03, p. 367-376, jul.-set. 2015.

FERRETTI. Marco, Antônio Carvalho; KNIJNIK, Jorge Dorfman. Mulheres podem praticar lutas? Um estudo sobre as representações sociais de lutadoras universitárias. Movimento. Rio Grande do Sul, v. 13, n. 01, p. $57-80$.

GLOBO ESPORTE. Mulheres invadem as artes marciais e mudam o ambiente nas academias. 2014.

Disponível em:

http://globoesporte.globo.com/pb/noticia/2014/12/mulheres-invadem-artes-marciais-e-mudam-o-ambiente-da s-academias.html. Acesso em: 14 abr. 2020. 
GOELLNER, Silvana Vilodre. A inserção da mulher no universo cultural do esporte. 2016. Disponível $\mathrm{em}$ : http://soesporte.com.br/a-insercao-da-mulher-no-universo-culturado-esporte/. Acesso em: 8 de mar. 2016.

GOELLNER, Silvana Vilodre.Mulher e esporte no Brasil: entre incentivos e interdições elas fazem história. Pensar a prática, v. 8, n. 1, p. 85-100, jan.-jun. 2005.

IBF. History. Springfiel. 2020. Disponível em:

https://www.ibf-usba-boxing.com/index.php/about/history-of-ibf. Acesso em: 01 abr. 2020.

JARDIM. Juliana Gomes. "IT'S TIME"! MMA Feminino, Mercado da Beleza e

Cis-heteronormatividade: Uma etnografia multissituada com lutadoras brasileiras. 2018. $200 \mathrm{f}$. Tese

(Doutorado apresentada ao Programa de Pós Graduação em Ciências Sociais). Faculdade de Filosofia e

Ciências da Universidade Estadual Paulista, USP, Marília, 2018.

KRIVOCHEIN, B. Menina de Ouro de Clint Eastwood. Zeta Filmes. Disponível em

http://www.zetafilmes.com.br/criticas/meninadeouro.asp?pag=meninadeouro . Acesso em: 25 out. 2019.

LOURO, Guacira Lopes. "Uma leitura da história da educação sob a perspectiva de gênero". Teoria e Educação, no 6. Porto Alegre, 1992, pp. 53-67.

LOVISOLO, H; SOARES, A. J.; BARTOLO, T. L. 2006. "Feministas, mulheres e esporte: questões metodológicas”. Revista Movimento. Porto Alegre, v.12, n. 03 p.165-191.

MARTINS, Carlos José; KANASHIRO, Cláudia. Bujutsu, budô, esporte de luta. Revista Motriz, v. 16, n. 3,2010 .

MCQUAIL, Denis.Teoria da comunicação de massas. Lisboa: Fundação Calouste Gulbenkian, 2003.

MELLO L. M. Meninos e meninas como reféns de uma sociedade sexista. Revista Motricidade. $\mathrm{N}^{\circ} 2$ Rio de Janeiro: 2002. Disponível em: http://www.castelobranco.br/prppg/revista/artigo.htm. Acesso em: 20 nov. 2019.

MOCARZEL, Rafael Carvalho da Silva. Artes marciais e jovens: violência ou valores educacionais? Um estudo de caso de um estilo de kung-fu. Universidade Salgado de Oliveira, Niterói 2011.

MONTEIRO. Luciana Botelho. O treinador de judô no Brasil. Rio de Janeiro: Sprint, 1998.

MOURA. Diego Luz. et al. Esporte, mulheres e masculinidades. Rio de Janeiro. ano 5, n 13, p. 02. 22 fev. 2010.

MOURÃO, Ludmila. Representação social da mulher brasileira nas atividades físico desportivas: da segregação à democratização. Movimento, n. 13, p. 5-18, 2000.

MOURÃO, Ludmila; SOUZA, Gabriela. C. Narrativas sobre o sul-americano de judô de 1979: a legalização do judô feminino no Brasil. In: XV Congresso Brasileiro de Ciências do Esporte/ II Congresso Internacional de Ciências do Esporte: Política Ciência e Produção do Conhecimento em Educação Física. GTT- Memórias da Educação Física e Esporte. Pernambuco, set. 2007.

MOURÃO, Ludimila. Vozes femininas e o Esporte Olímpico no Brasil. in: TURINO, M.; DACOSTA, L. (org.). Coletânea de textos em estudos olímpicos. Rio de Janeiro: Gama Filho, 2002. V. 1, p. 831-849.

NASCIMENTO, Paulo Rogério Barbosa do; ALMEIDA, Luciano de. A tematização das lutas na educação física escolar: restrições e possibilidades. Revista Movimento, v.13, n. 3, 2007. 
PINI, Mario Carvalho. A mulher no esporte: fisiologia esportiva. Rio de Janeiro: Guanabara Koogan, 1978. p. 204-220.

PRODANOV. Cleber Cristiano; FREITAS. Ernani. César. Metodologia do trabalho científico: Métodos e Técnicas da Pesquisa e do Trabalho Acadêmico. 2. ed. Rio Grande do Sul: Nova Hamburgo, 2013.

REDE NACIONAL DO ESPORTE. Igualdade de gênero: uma luta histórica que encontrou acolhida nos Jogos da Juventude. Site. 2018. Disponível em:

http://rededoesporte.gov.br/pt-br/noticias/igualdade-de-genero-uma-luta-historica-que-encontrou-esperanca-n os-jogos-olimpicos-da-juventude. Acesso: 14 abr. 2020.

REDE NACIONAL DO ESPORTE. Rosicleia Campos: técnica e testemunha da história do judô. Site. 2018. Disponível em:

http://rededoesporte.gov.br/pt-br/noticias/rosicleia-campos-tecnica-e-testemunha-da-historia-no-judo. Acesso em: 12 nov. 2020.

SILVA, Daniel Sousa. et al. Jiu-Jitsu feminino- De promessa a realidade mundial. Revista Ciência Atual. Rio de Janeiro. v. 13, n 1, p. 02-17, 2019. Disponível em: http://inseer.ibict.br/cafsj. Acesso em: 19 out. 2019.

SILVA, Gisele Passeri. Histórico da mulher no judô, preconceitos, estereótipos e discriminações. Revista Motrivivência. Rio de Janeiro, n. 13447, p. 196-207, dez 1994. Disponível em: https://periodicos.ufsc.br/index.php/motrivivencia/article/viewFile/14666/13447 . Acesso em: 19 out. 2019.

SÓ HISTÓRIA. Joana d'Arc. Virtuos Tecnologia da Informação, 2009. Disponível em: http://www.sohistoria.com.br/biografias/joanadarc/. Acesso em: 22 nov. 2019.

SOBRINHO. Educação physica feminina. Rio de Janeiro: Typografia do Patronato, 1930.

SOUZA, Gabriela Conceição. Trajetórias e percepções no judô feminino brasileiro de alto rendimento. 2016. 175 f. Tese (Doutorado Ciências do exercício e do esporte) - Universidade do Estado do Rio de Janeiro, Rio de Janeiro.2016.

SOUZA, Eustáquia Salvadora.; ALTMANN, Helena. Meninos e meninas: Expectativas corporais e implicações na educação física escolar. Cadernos CEDES, Campinas, v. 19, n.48, p.52-68, 1999.

SOUZA, Pedro. A nova geração de faixas pretas que vem mudando o cenário do Jiu-Jitsu Feminino. Disponível em BJJForum:

http://bjjforum.com.br/a-nova-geracao-defaixas-pretas-que-vem-mudando-o-cenario-do-jiu-jitsu-feminino/. Acesso em: 31 mar. 2020.

SUPERPROF. Mulheres que se destacaram nos esportes de combate. 2019. Disponível em: $\mathrm{https}$ ://www.superprof.com.br/blog/mulheres-que-se-destacaram-nos-esportes-de-combate/. Acesso em: 25 out. 2019.

THOMAS. J. R; NELSON. J. K. Métodos de pesquisa em atividade física. 3. ed. Porto Alegre: Artmed, 2002.

THOMAZINI, Samuel O.; MORAES, Cláudia Emília A.; ALMEIDA, Felipe Q. Controle de si, dor e representação feminina entre lutadores(as) de Mixed Martial Arts. Pensar a prática, v. 11, n. 3, p. 281-290, set.-dez. 2008.

THORNE, Barrie. Gender play: Girls and boys in school. New Jersey: Rutgers University Press, 1993, $237 \mathrm{pp}$. 
U.F.C. Ranking dos Atletas. 2019. Disponível em:

https://www.ufc.com.br/rankings?rankings_panelist=1082. Acesso em: 19 out. 2019.

WHITE, Dana. Ronda Rousey faz história e será a primeira mulher no hall da fama do UFC. UFC. 2018. Disponível em:

https://www.ufc.com.br/news/ronda-rousey-faz-historia-e-sera-primeira-mulher-no-hall-da-fama-do-ufc. Acesso em: 02 abr. 2020.

\section{NOTAS DE AUTOR}

\section{AGRADECIMENTOS}

Agradeço aos professores Kátia Danailof e Luiz Gustavo Bonatto Rufino pelas correções e ensinamentos ao longo desse trabalho, contribuindo com uma visão crítica e aperfeiçoando mais o trabalho.

CONTRIBUIÇÃO DE AUTORIA - Não se aplica.

FINANCIAMENTO - Não se aplica.

CONSENTIMENTO DE USO DE IMAGEM - Não se aplica.

APROVAÇÃO DE COMITÊ DE ÉTICA EM PESQUISA - Não se aplica.

CONFLITO DE INTERESSES - Não se aplica.

\section{LICENÇA DE USO}

Os autores cedem à Motrivivência - ISSN 2175-8042 os direitos exclusivos de primeira publicação, com o trabalho simultaneamente licenciado sob a Licença Creative Commons Attribution Non-Comercial ShareAlike (CC BY-NC SA) 4.0 International. Esta licença permite que terceiros remixem, adaptem e criem a partir do trabalho publicado, desde que para fins não comerciais, atribuindo o devido crédito de autoria e publicação inicial neste periódico desde que adotem a mesma licença, compartilhar igual. Os autores têm autorização para assumir contratos adicionais separadamente, para distribuição não exclusiva da versão do trabalho publicada neste periódico (ex.: publicar em repositório institucional, em site pessoal, publicar uma tradução, ou como capítulo de livro), com reconhecimento de autoria e publicação inicial neste periódico, desde que para fins não comerciais e compartilhar com a mesma licença.

\section{PUBLISHER}

Universidade Federal de Santa Catarina. Programa de Pós-Graduação em Educação Física. LaboMídia - Laboratório e Observatório da Mídia Esportiva. Publicado no Portal de Periódicos UFSC. As ideias expressadas neste artigo são de responsabilidade de seus autores, não representando, necessariamente, a opinião dos editores ou da universidade.

\section{EDITORES}

Mauricio Roberto da Silva, Giovani De Lorenzi Pires, Rogério Santos Pereira.

\section{EDITOR DE SEÇÃO}

Juliano Silveira. 


\section{REVISÃO DO MANUSCRITO E METADADOS}

João Caetano Prates Rocha; Keli Barreto.

\section{HISTÓRICO}

Recebido em: 08 de setembro de 2020.

Aprovado em: 03 de dezembro de 2020. 